\title{
HIDROESTRATIGRAFIA DO GRUPO BAURU (K) NO ESTADO DE SÃO PAULO
}

\section{HYDROSTRATIGRAPHY OF THE BAURU GROUP IN SÃO PAULO STATE, BRAZIL}

\author{
Flávio de Paula e Silva ${ }^{1}$, Chang Hung Kiang ${ }^{1}$ e Maria Rita Caetano-Chang ${ }^{1}$
}

Recebido em 20/03/2005, aceito em 06/09/2005

RESUMO Perfis geofísicos, descrições de amostras de calha e de testemunhos de sondagem de poços perfurados para extração de água subterrânea possibilitaram identificar e correlacionar as diferentes unidades hidroestratigráficas e avaliar o potencial hídrico do Sistema Aquífero Bauru, no Estado de São Paulo. Foram identificados os aquíferos Caiuá, Santo Anastácio, Birigüi, Adamantina e Marília, e os aqüitardos Pirapozinho e Araçatuba. As unidades aquíferas foram diferenciadas, em termos de isólitas de permeabilidade aparente relativa, em muito permeáveis e moderadamente permeáveis. Os mapas de isólitas refletem, diretamente, as regiões hidraulicamente mais favoráveis à produção de água. Isólitas de arenito de elevada permeabilidade aparente do Aqüífero Caiuá indicaram melhor potencial hídrico na região sudoeste de ocorrência do Grupo Bauru, o mesmo sucedendo com o Aqüífero Santo Anastácio. No Aqüífero Birigüi, as zonas com melhor potencial hídrico concentraram-se em faixa alongada na porção central de sua área de ocorrência. Para o Aqüífero Adamantina, as isólitas de moderada a elevada permeabilidade aparente mostraram zonas de maior potencial hídrico distribuídas em faixas paralelas, a sul e a norte do Rio Tietê. Para o Aqüífero Marília, os perfis de resistividade analisados refletem, principalmente, a intensa cimentação carbonática das litologias, dificultando a distinção entre arenitos de elevada e de moderada permeabilidade aparente. O Sistema Aqǘfero Bauru possui reserva permanente de água estimada em pouco mais de $1.600 \mathrm{~km}^{3}$, distribuída pelos aqüíferos Caiuá $\left(150 \mathrm{~km}^{3}\right)$, Santo Anastácio $\left(560 \mathrm{~km}^{3}\right)$, Birigüi $\left(15 \mathrm{~km}^{3}\right)$, Adamantina $\left(810 \mathrm{~km}^{3}\right)$ e Marília $\left(80 \mathrm{~km}^{3}\right)$.

Palavras-chave: Aqüífero Bauru, hidroestratigrafia, perfis geofísicos.

\begin{abstract}
Geophysical logs, ditch samples and cores of water wells drilled in São Paulo State, Brazil, allowed the identification and correlation of different hydrostratigraphics units and the evaluation of hydraulic potential of the Bauru Aquifer System (Mesozoic of Paraná Basin). Identified units were Caiuá, Santo Anastácio, Birigüi, Adamantina and Marília aquifers, and Pirapozinho and Araçatuba aquitards. The aquifer units were differentiated in terms of isoliths of relative apparent permeability, as very permeable and moderately permeable. The isolith maps contemplate directly the most favorable potential areas to water production. The isoliths of high apparent permeability sandstone of Caiuá and Santo Anastácio aquifers showed larger concentrated values in the southwest occurrence area of the Bauru Group. The areas with best hydraulic potential for Birigüi Aquifer are concentrated on elongated strip along the center of his occurrence area. Adamantina Aquifer showed moderate and high isoliths of apparent permeability distributed in parallel strips to south and north of Tietê River. Resistivity logs of Marília Aquifer contemplate mainly the intense carbonatic cementation of the lithologies, hindering the distinction between high and moderate apparent permeability of its sandstones. The static water storage of the Bauru Aquifer System is about $1.600 \mathrm{~km}^{3}$, distributed by the Caiuá $\left(150 \mathrm{~km}^{3}\right)$, Santo Anastácio $\left(560 \mathrm{~km}^{3}\right)$, Birigüi $\left(15 \mathrm{~km}^{3}\right)$, Adamantina $\left(810 \mathrm{~km}^{3}\right)$ and Marília $\left(80 \mathrm{~km}^{3}\right)$ aquifers.
\end{abstract}

Keywords: Bauru Aquifer System, hydrostratigraphy, well logs.

\section{INTRODUÇÃO}

O Grupo Bauru compreende uma sucessão de rochas sedimentares cretáceas depositadas na porção centro-setentrional da Bacia do Paraná, sobre substrato predominantemente basáltico da Formação Serra Geral, durante o último episódio significativo de sedimentação desta unidade geotectônica.

No Estado de São Paulo, a área de afloramento do Grupo Bauru é de cerca de $117.000 \mathrm{~km}^{2}$ (DAEE, 1990), correspondente a $47 \%$ do território paulista, e abrange em seus domínios importantes cidades como São José do Rio Preto, Araçatuba, Araraquara, Votuporanga, Presidente Prudente, Marília, Tupã, Lins, Bauru, Dracena, Andradina, Fernandópolis e outras.
Nestas e nas demais cidades circunscritas, a água subterrânea, armazenada nos sedimentos do Grupo Bauru e extraída através de poços tubulares, representa a fonte principal ou alternativa de obtenção de recursos hídricos, seja para abastecimento público, industrial, comercial, rural ou doméstico, sustentando o desenvolvimento econômico regional e a qualidade de vida das populações que dela se utilizam. Dos 645 municípios do Estado de São Paulo, 462 (71,6\%) são abastecidos, parcial ou integralmente, por água subterrânea dos diversos aquíferos existentes. Destes, 240 municípios (52\%) captam água do Sistema Aqǘf́ero Bauru, sendo que em 210 (45\%) o abastecimento é integralmente feito por água subterrânea (Figura $1)$.

${ }^{1}$ Instituto de Geociências e Ciências Exatas da Universidade Estadual Paulista (UNESP), Campus de Rio Claro. (flaviops@rc.unesp.br), (chang@rc.unesp.br), (mrchang@rc.unesp.br). 
Pelo fato de estar inteiramente aflorante, este aqüífero pode facilmente ser acessado por escavações e perfurações de baixo custo, fornecendo, na maioria dos casos, a vazão desejada pelos usuários. Pela mesma razão, temse mostrado extremamente vulnerável à infiltração de contaminantes orgânicos e inorgânicos (DAEE, 1976, 1979).

As vazões obtidas em perfurações no Sistema Aqüífero Bauru são extremamente variáveis em virtude de sua reconhecida diversidade litofaciológica, que coloca em contato, lateral e vertical, sedimentos com diferentes características de porosidade e permeabilidade. A utilização da expressão "Aqüífero Bauru", de acordo com Vieira (1981), nem sempre é adequada, já que em muitas de suas porções esse sistema representa mais de um aqüífero ou autênticos aqüicludes.

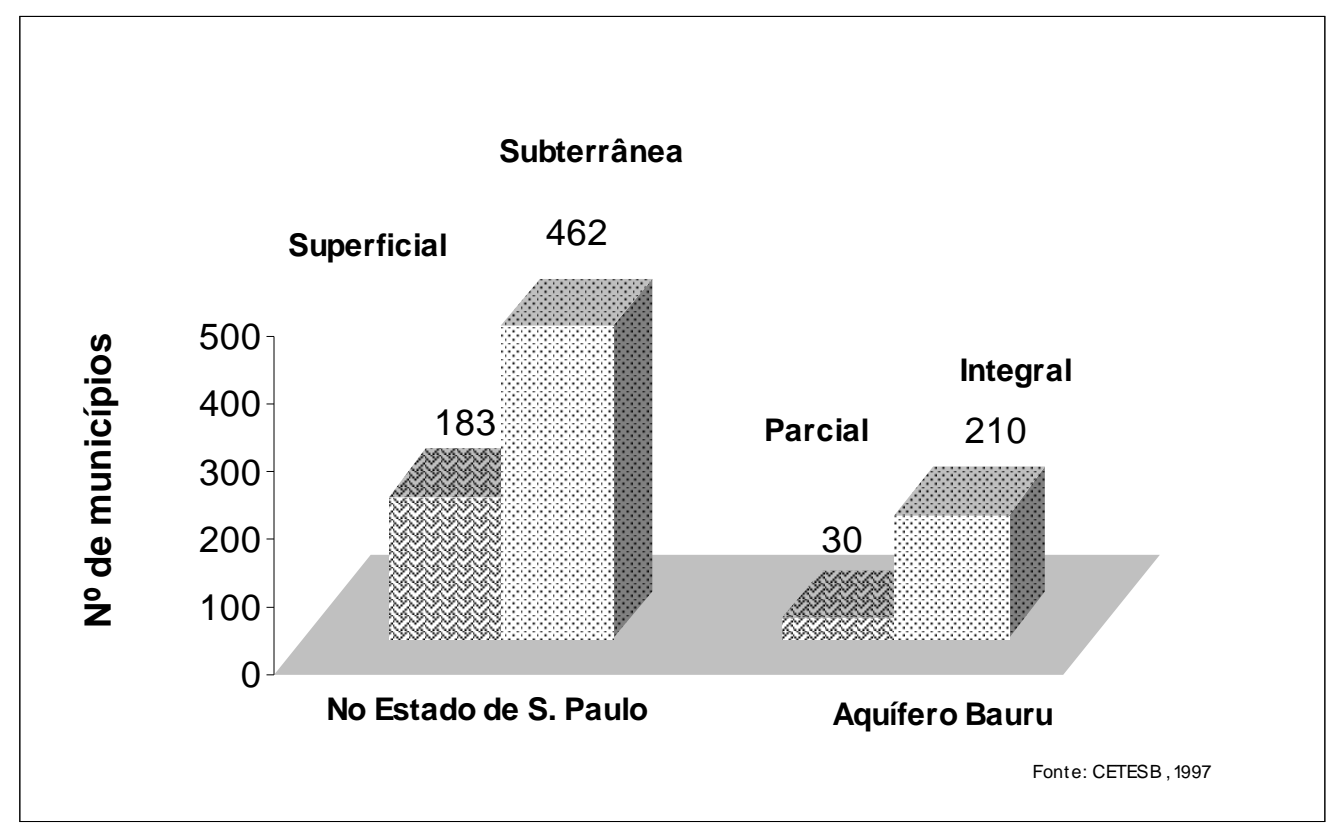

Figura 1 - Comparação entre o número de municípios que se utilizam de água superficial e subterrânea para abastecimento público no Estado de São Paulo e entre os municípios que se utilizam, parcial ou integralmente, de água subterrânea do Sistema Aqüífero Bauru (CETESB, 1997).

Figure 1 - Comparison among the number of cities that use superficial and underground water for public provisioning in the São Paulo State and among the cities that use, partial or integrally, underground water of the Bauru Aquifer System (CETESB, 1997).

A qualidade precária das informações existentes nos relatórios de perfuração de poços das empresas e órgãos do setor sempre se constituiu em obstáculo à identificação e à delimitação das diversas zonas aqüíferas do Sistema Bauru, dificultando o estabelecimento de uma correlação entre os aspectos litoestratigráficos e seu potencial hídrico. Essa preocupação havia sido manifestada há muito pelo Departamento de Águas e Energia Elétrica do Estado de São Paulo - DAEE (1976), quando dos Estudos de Águas Subterrâneas nas Regiões Administrativas 7,8 e 9, ao admitir que o conhecimento hidrogeológico daquele momento "não permitia uma demarcação clara das regiões mais permeáveis e nenhuma correlação com a situação geológica".

Com o crescente emprego e desenvolvimento da técnica de perfilagem geofísica em poços perfurados por órgãos e empresas estatais paulistas, iniciada no final da década de 70 , e com o surgimento dos equipamentos computadorizados no início dos anos 90, a qualidade das informações geológicas melhorou significativamente, ampliando os horizontes da pesquisa hidrogeológica em áreas sedimentares.

Com base na utilização de perfis geofísicos convencionais e computadorizados (radioativos, elétricos e acústicos), de descrições de amostras de calha e de testemunhos de sondagem, obtidos de perfurações efetuadas para extração de água subterrânea, foi possível identificar e correlacionar as diferentes unidades hidroestratigráficas e avaliar qualitativamente o potencial hídrico do Sistema Aqüífero Bauru, em âmbito do Estado de São Paulo. A escassez de parâmetros hidrodinâmicos medidos "ïn situ" não permitiu a caracterização das unidades aqüíferas com base nas propriedades de condutividade hidráulica, transmissividade, porosidade efetiva e coeficiente de armazenamento. 


\section{BASE DE DADOS}

A base de dados utilizada nesta pesquisa foi extraída, principalmente, de arquivos de relatórios de perfuração de poços do Departamento de Águas e Energia Elétrica do Estado de São Paulo - DAEE e Companhia de Saneamento Básico do Estado de São Paulo SABESP e, em menor número, de empresas particulares do ramo de perfuração e de trabalhos realizados por este autor, constando de perfis litoestratigráficos, de descrições de amostras de calha e de perfis geofísicos, convencionais e computadorizados.

Foram utilizados 180 perfis geofísicos, abrangendo 175 localidades diferentes do Estado de São Paulo, entre municípios, distritos e vilas. Destes, 52 correspondem a perfis calibrados, em geral com curvas de potencial espontâneo, raios gama API (American Petroleum Institute), resistividade normal curta, resistividade induzida e velocidade sônica, processados por equipamentos computadorizados, cujos registros das propriedades petrofísicas podem ser utilizados para análises quantitativas. Os demais 128 perfis são designados convencionais, sem calibração API, apresentando curvas de raios gama em cps (counts per second), potencial espontâneo, resistência e resistividade 16 e 64 polegadas, podendo ser utilizados somente para análises qualitativas.

A pesquisa bibliográfica também permitiu reunir cerca de 50 perfis litológicos elaborados com base na descrição de testemunhos de sondagem de poços perfurados pelo Instituto Geológico - IG, publicados nos trabalhos de Arid (1966), Mezzalira (1974) e Barcha (1980).

Amostras de calha, armazenadas na litoteca da regional de Araraquara do Departamento de Águas e Energia Elétrica do Estado de São Paulo - DAEE, também foram reexaminadas quando necessário, para calibração dos perfis.

\section{CONCEITO DE UNIDADE HIDROESTRATIGRÁFICA}

Unidade hidroestratigráfica pode ser definida como a parte de um corpo rochoso que forma uma unidade hidrogeológica distinta em relação ao fluxo de água (MAXEY, 1964, apud SEABER, 1988). Revisando este conceito, Seaber (1988) redefiniu-a como "um corpo rochoso distinguido e caracterizado por sua porosidade e permeabilidade". Desse modo, o arcabouço geológico pode ser subdividido em porções mais permeáveis ou menos permeáveis (aqüíferos e aqüitardos, respectivamente), auxiliando na determinação do sistema de fluxo regional.

Águas Subterrâneas, v.19, n.2, p.19-36, 2005
A definição de unidades hidroestratigráficas, em escala regional, envolve: conceitos estratigráficos, de modo a estabelecer-se o arcabouço conceitual geral dos depósitos; mapeamento de subsuperfície utilizando informações de testemunhos, perfis geofísicos, amostras de calha e dados de perfuração, de modo a identificar-se as litofácies; testes de laboratório em amostras de testemunhos dos aqüíferos e aqüitardos; testes de bombeamento in situ dos aquíferos e aqüitardos para determinação de suas características hidrodinâmicas; e pesquisa sobre os efeitos modificadores derivados dos processos diagenéticos e tectônicos nas propriedades dos aqǘf́ros, ao longo de sua história evolutiva.

\section{AVALIAÇÃO DO POTENCIAL HÍDRICO ATRAVÉS DE PERFIS GEOFÍSICOS}

A dificuldade de obtenção de parâmetros hidrodinâmicos (condutividade hidráulica " $K$ ", transmissividade "T", porosidade específica "Øe" e coeficiente de armazenamento "S"), in situ, torna os perfis geofísicos calibrados uma ferramenta auxiliar de grande importância na avaliação das formações produtoras de água. Estas ferramentas, desenvolvidas e amplamente empregadas na indústria petrolífera mundial, vêm sendo crescentemente utilizadas na pesquisa de água subterrânea.

Os perfis geofísicos não fornecem medidas diretas de produtividade e nem de valores de condutividade hidráulica (permeabilidade) e de porosidade efetiva, mas permitem estabelecer, com precisão, as espessuras das camadas aqüíferas, fornecendo indicações sobre a granulometria, as zonas mais permeáveis do arcabouço sedimentar e a porosidade total da rocha.

Archie (1941, apud BALAN et al., 1995) proporcionou as bases para a interpretação quantitativa de perfis. Analisando as resistividades, em laboratório, de grande número de testemunhos saturados por água salgada, introduziu o conceito de fator de formação (F), de acordo com a relação:

$$
\left.F=\frac{R o}{R w} \quad \text { (equação } 1\right)
$$

onde

$\mathrm{F}=$ fator de formação

Ro $=$ resistividade da formação saturada com água

$\mathrm{Rw}=$ resistividade da água de formação

Archie (1941, apud BALAN et al., 1995) estabeleceu que o fator de formação (F) é função do tipo e das características da formação e varia, dentre outras propriedades, com a porosidade 
efetiva e a permeabilidade das rochas reservatório:

$$
F=\frac{a}{\phi^{m}}
$$

onde:

$\mathrm{a}=$ coeficiente litológico ou de tortuosidade

$\varnothing=$ porosidade efetiva da formação

$\mathrm{m}=$ coeficiente de cimentação

Relacionando-se as duas equações anteriores em termos da resistividade da formação, tem-se:

$$
\left.R o=\frac{a \cdot R w}{\phi^{m}} \quad \text { (equação } 3\right)
$$

Assim expressa, a resistividade de uma formação totalmente saturada por água relacionase diretamente à resistividade da água contida em seus poros e inversamente à porosidade da rocha. $\mathrm{O}$ expoente " $\mathrm{m}$ " e o coeficiente " $\mathrm{a}$ " variam de rocha para rocha e podem ser determinados em medidas laboratoriais. Para rochas pouco ou nada cimentadas, os valores destes parâmetros são definidos em Schlumberger (1972) como:

$$
\mathrm{a}=0,62 \quad \text { e } \quad \mathrm{m}=2,15
$$

Assim, a resistividade da formação é dada por:

$$
R o=\frac{0,62 \cdot R w}{\phi^{2,15}}
$$

Estas relações empíricas estão bem estabelecidas para formações portadoras de águas salinas, uma vez que todas pesquisas neste campo foram desenvolvidas para atender a atividade exploratória petrolífera. Para formações portadoras de água doce, o efeito da condutância superficial dos grãos do arcabouço rochoso não pode ser desprezado. Esta propriedade física é incrementada com a diminuição da salinidade da água intersticial e faz com que o fator de formação decresça com o aumento da resistividade da água e com a diminuição da granulometria dos sedimentos. Neste caso, o fator de formação torna-se dependente da resistividade da água intersticial e do tamanho dos grãos (Figura 2), bem como da porosidade.

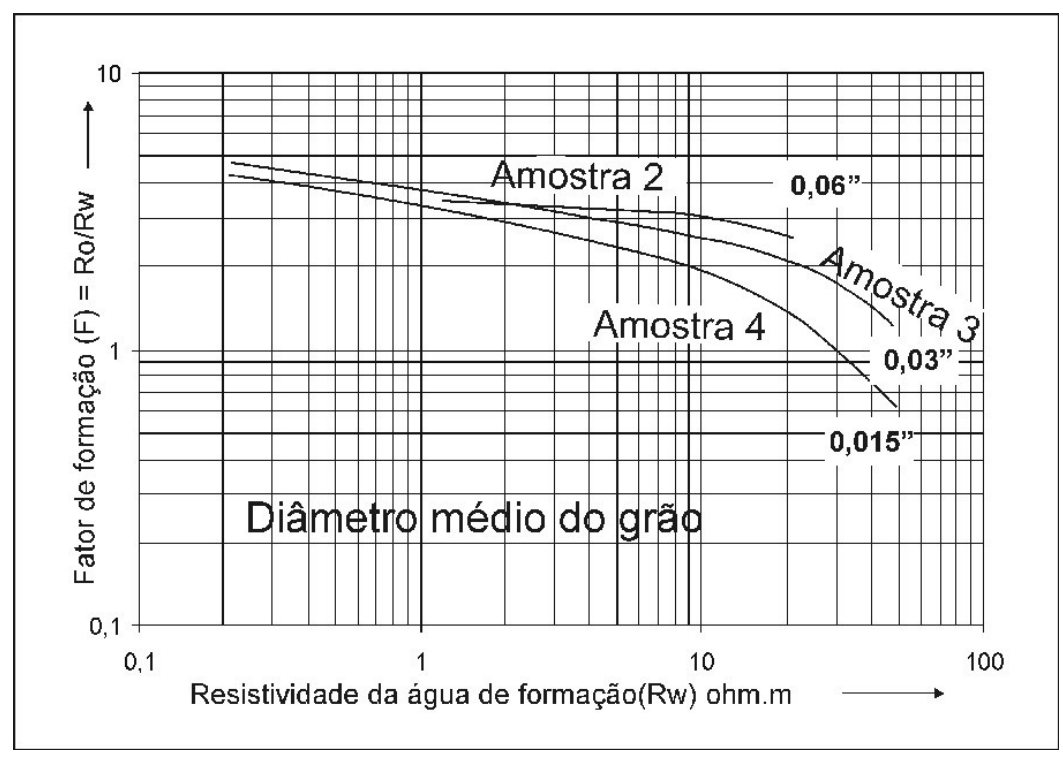

Figura 2 - Relação entre fator de formação (F), resistividade da água de formação (Rw) e diâmetro dos grãos (modificado de SARMA; RAO, 1963, in SCHLUMBERGER, 1974).

Figure 2 - Relation among formation factor $(F)$, formation water resistivity $(R w)$ and diameter of the grains (modified of SARMA; RAO, 1963, in SCHLUMBERGER, 1974).

A variação do fator de formação com a granulometria, assim como a clássica relação entre aumento da granulometria e incremento da permeabilidade, têm sido reportadas por diversos autores (SCHLUMBERGER, 1974). Para uma certa resistividade da água e porosidade do aquífero, o efeito da condutância superficial aumentará com a diminuição da granulometria e, por extensão, da permeabilidade do sedimento.

$\mathrm{Na}$ prática, todos estes fatores, como concentração baixa de sólidos dissolvidos na água, aumento da granulometria (e consequientemente da permeabilidade) e baixo conteúdo argiloso, produzirão um incremento do fator de formação, correspondente a um 
incremento da resistividade registrada pelos perfis. Desse modo, as melhores zonas aquiíferas serão indicadas pelas maiores resistividades (SCHLUMBERGER, 1974). Ressalvas devem ser feitas no caso de sedimentos arenosos com alto grau de cimentação, ou seja, pouco porosos, que podem apresentar elevadas resistividades; todavia, os perfis de porosidade poderão auxiliar nesta questão. Já os sedimentos pelíticos mostram alta porosidade, águas intersticiais proporcionalmente mais ricas em sais e elevada condutância superficial, o que os faz mais condutivos do que os sedimentos arenosos. Da mesma forma, os argilominerais disseminados nos espaços porosos do arcabouço sedimentar reduzem a resistividade dos aquíferos, proporcionalmente à quantidade de argila presente (GUYOD, 1966).

Esta relação direta entre resistividade e permeabilidade fornece as bases para a interpretação qualitativa de perfis em zonas aquíferas portadoras de água doce. Interpretações quantitativas, contudo, necessitam de calibrações rocha-perfil, as quais devem ser feitas preferencialmente em áreas com quantidade razoável de dados confiáveis, de acordo com metodologia descrita por Nery

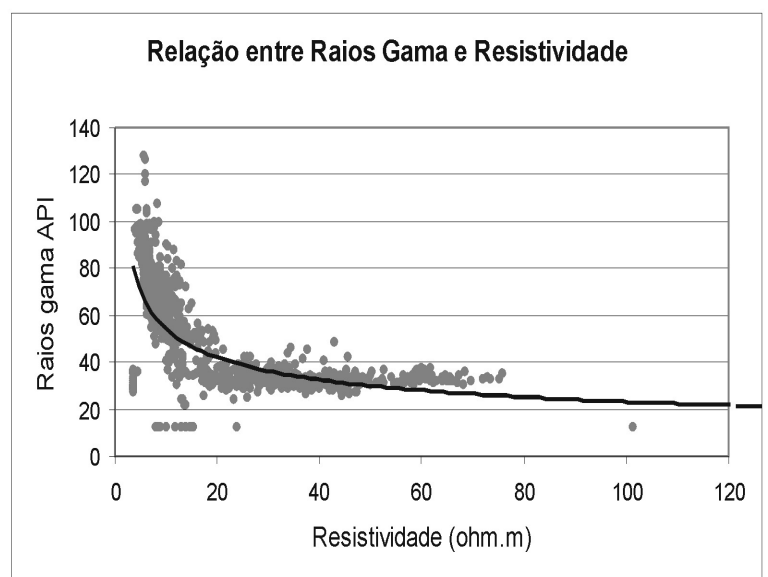

(1995), não podendo prescindir de parâmetros extraídos dos testemunhos de sondagem. No estágio atual de desenvolvimento das pesquisas sobre águas subterrâneas no Estado de São Paulo, ainda não é possível a realização de estudos de natureza quantitativa, baseados em perfis geofísicos de poços profundos, de modo que as avaliações conduzidas neste trabalho foram baseadas somente em seus aspectos qualitativos.

A identificação de zonas potencialmente mais permeáveis foi feita através da análise dos perfis de resistividade, com auxílio dos perfis de raios gama, de potencial espontâneo e de tempo de trânsito sônico.

As correlações entre leituras de raios gama versus resistividade, e tempo de trânsito sônico versus resistividade, mostradas na figura 3, demonstram que os valores mais altos de resistividade quase sempre se associam aos valores mais baixos de argilosidade, indicados pelos raios gama, e aos valores mais baixos de porosidade, indicados pelo tempo de trânsito sônico. Estas relações atestam que o conteúdo argiloso representa o principal fator na diminuição dos valores de resistividade das formações aquiíferas estudadas.

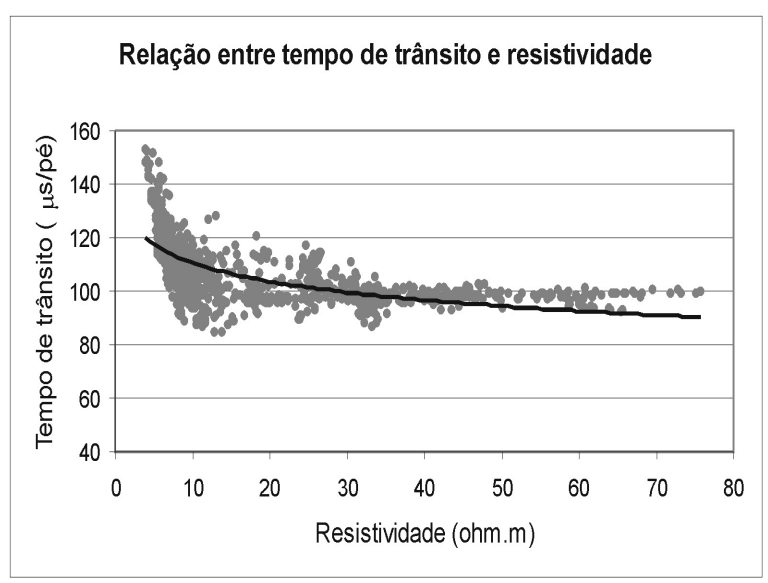

Figura 3 - Correlação raios gama API versus resistividade e tempo de trânsito sônico versus resistividade, de perfil geofísico de poço perfurado em Álvares Machado - SP (modificado de PAULA e SILVA, 2003).

Figure 3 - Correlation among gamma ray versus resistivity and sonic transit time versus resistivity of well log drilled in Álvares Machado - SP (modified of PAULA e SILVA, 2003).

Consequientemente, as zonas mais permeáveis são aquelas com maiores resistividades. Seguindo esta lógica, foram estabelecidos valores limites de resistividade para intervalos considerados impermeáveis, pouco permeáveis e muito permeáveis, de acordo com a análise individual dos perfis de cada poço.

Não existem valores padronizados para este tipo de análise mas, de modo geral, valores de resistividade inferiores a 10 ohm.m são indicativos de materiais predominantemente pelíticos, acima de 20 ohm.m são indicativos de areias bem permeáveis, e entre 10 e $20 \mathrm{ohm} . \mathrm{m}$ de areias moderadamente permeáveis.

Com base nestes valores, foi possível determinar, em cada poço, as espessuras totais dos intervalos correspondentes aos sedimentos relativamente pouco permeáveis, moderadamente permeáveis e muito permeáveis e expressar esses resultados através de mapas de isólitas, permitindo o cálculo volumétrico desses materiais. Uma vez que transmissividade é 
definida como o produto da espessura pela condutividade hidráulica, os mapas de isólitas de permeabilidade relativa dos arenitos refletem, diretamente, as zonas hidraulicamente mais favoráveis à produção de água, ainda que no atual estágio do conhecimento hidrogeológico do Sistema Aquiífero Bauru não estejam disponíveis dados de campo destes parâmetros hidrodinâmicos.

\section{UNIDADES LITOESTRATIGRÁFICAS GRUPO BAURU}

A primeira coluna estratigráfica formal dos sedimentos cretáceos suprabasálticos foi proposta por Soares et al. (1980), a partir da integração de diversos trabalhos anteriores de mapeamento regional. Nesta proposta, os autores elevaram os sedimentos "Bauru" à categoria de Grupo e subdividiram-no nas formações Caiuá, Santo Anastácio, Adamantina e Marília (Figura 4).

Posteriormente, Barcelos; Suguio (1987) propuseram a subdivisão da Formação Adamantina nos membros Araçatuba e São José do Rio Preto, e a subdivisão da Formação Marília nos membros Ponte Alta, Echaporã e Serra da Galga.

A partir de 1992, foram esboçadas novas concepções sobre gênese e relações estratigráficas das unidades do Grupo Bauru, contrapondo-se à versão operacional clássica de Soares et al. (1980).

Fernandes (1992) dividiu a unidade Caiuá em formações Goio Erê e Rio Paraná, elevando-a, conseqüentemente, à categoria de grupo. Posteriormente, Fernandes; Coimbra (1994) propuseram a definição formal do Grupo Caiuá, reunindo as formações Rio Paraná, Goio Erê e Santo Anastácio. Em decorrência, o Grupo Bauru passou a comportar apenas as formações
Adamantina, Marília e Uberaba (esta de ocorrência restrita ao Triângulo Mineiro) e as rochas admitidas como extrusivas, designadas de Analcimitos Taiúva, intercaladas na primeira.

Analisando a distribuição e as relações das associações de fácies da seqüência cretácea suprabasáltica da Bacia do Paraná, em sua parte oriental, Fernandes (1998) manteve a distinção entre os grupos Caiuá e Bauru: o primeiro agrupando as formações Rio Paraná, Goio Erê e Santo Anastácio, proposta por Fernandes; Coimbra (1994), e o segundo subdividido em formações Uberaba, Vale do Rio do Peixe, Araçatuba, São José do Rio Preto, Presidente Prudente e Marília, mais os analcimitos Taiúva, ficando extinta a consagrada designação Adamantina.

Utilizando dados de poços e de perfis geofísicos e aplicando critérios de correlação e interpretação baseados em superfícies de discordância regionais, Paula e Silva (2003) e Paula e Silva et al. (2003, 2004) reconheceram unidades geofísicas, em subsuperfície, correspondentes às unidades litoestratigráficas formais atribuídas ao Grupo Bauru, no Estado de São Paulo. As unidades reconhecidas foram as formações Caiuá, Santo Anastácio, Adamantina e Marília, segundo a concepção de SOARES et al. (1980), mais a Formação Araçatuba, de acordo com redefinição de Batezelli et al. (1999). Foram ainda identificadas duas novas formações, de ocorrência restrita à subsuperfície, designadas de Pirapozinho e Birigüi.

A figura 4 mostra a área de ocorrência das unidades litoestratigráficas do Grupo Bauru (segundo SOARES et al., 1980) no Estado de São Paulo, de acordo com IPT (1981), e a localização dos poços com perfis geofísicos estudados. 

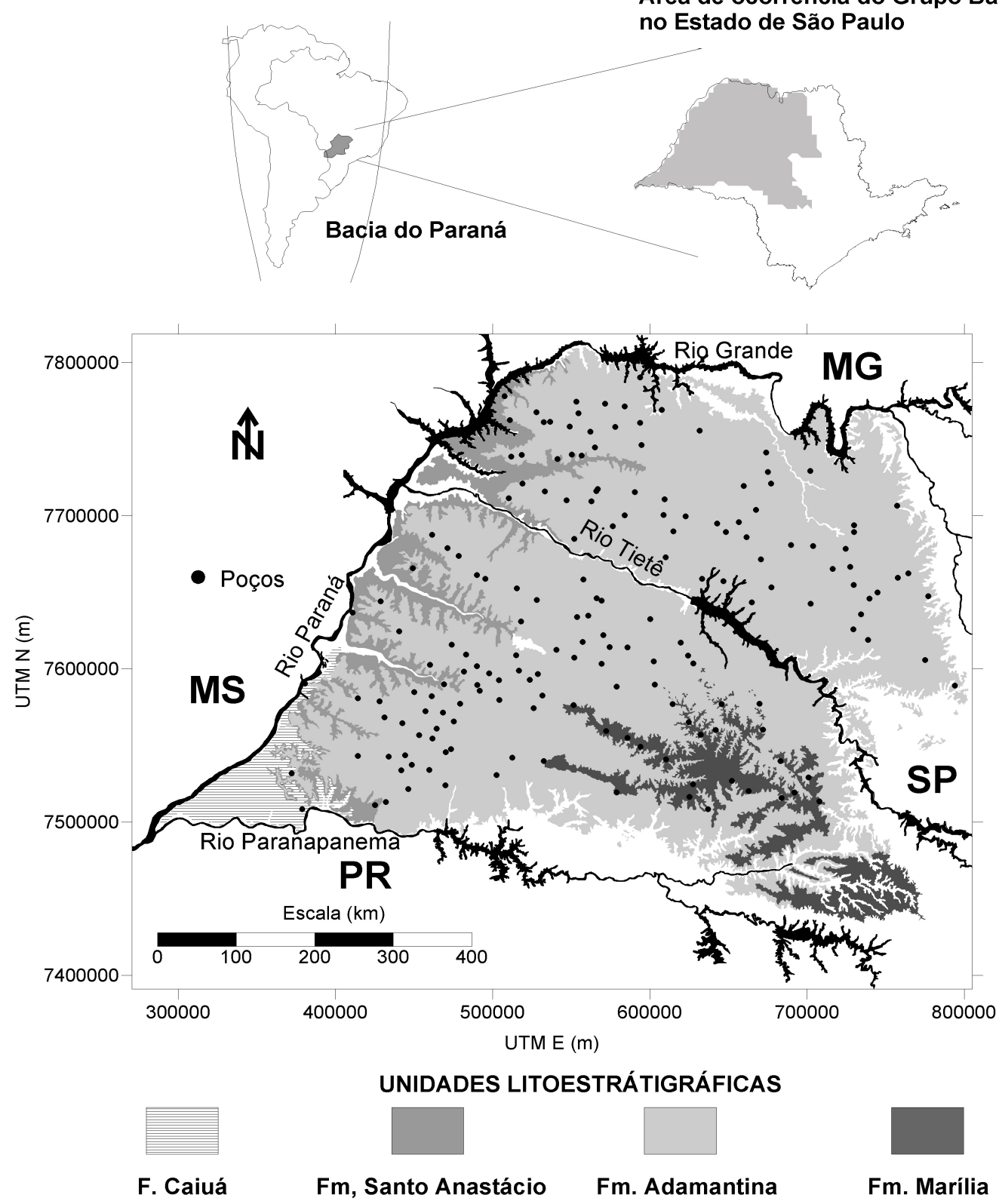

Figura 4 - Ocorrência das unidades litoestratigráficas do Grupo Bauru em superfície (IPT, 1981) e localização dos poços com perfis geofísicos estudados.

Figure 4 - Occurrence of the lithostratigraphic units of the Bauru Group in surface (IPT, 1981) and location of the studied wells with geophysical logs.

\section{UNIDADES HIDROESTRATIGRÁFICAS DO GRUPO BAURU}

A subdivisão hidroestratigráfica do Sistema Aqüífero Bauru no Estado de São Paulo, apresentada neste trabalho, baseou-se na litoestratigrafia de subsuperfície proposta por Paula e Silva (2003) e Paula e Silva et al. (2003, 2004). Assim, foram identificados os aqüíferos Marília, Adamantina, Birigüi, Santo Anastácio e Caiuá, e os aquiitardos Araçatuba e Pirapozinho, cujas relações hidroestratigráficas são apresentadas na figura 5 .

Justifica-se esta segmentação em unidades hidroestratigráficas em razão das particularidades litológicas de cada formação geológica, que por sua vez governam as propriedades hidráulicas do meio poroso. Portanto, é aqui admitida a correspondência entre unidades litoestratigráficas e hidroestratigráficas na partição do Sistema Aquíífero Bauru. 


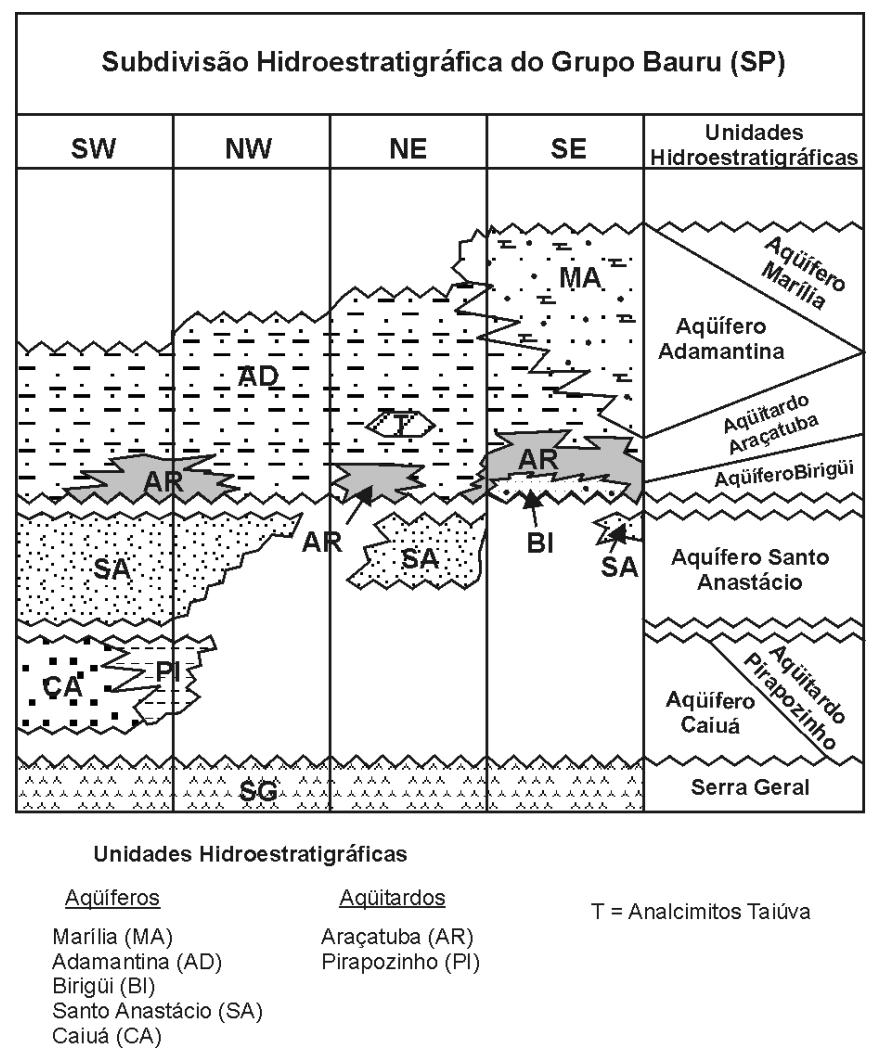

Figura 5 - Subdivisão hidroestratigráfica do Sistema Aqüífero Bauru (modificado de (PAULA e SILVA, 2003). Figure 5 - Hydrostratigraphic subdivision of the Aquifer Bauru System (modified of (PAULA e SILVA, 2003).

\section{Aqüífero Caiuá}

O Aqüífero Caiuá aflora em pequena extensão na região do Pontal do Paranapanema e nas proximidades do Rio Paraná, estando encoberto pelas unidades aqüíferas mais jovens no restante dos $31.000 \mathrm{~km}^{2}$ de sua área de ocorrência. Compreende sedimentos arenosos depositados em ambiente fluvial (interpretado apartir de curvas dos perfis geofísicos e das descrições de amostras de calha por Paula e Silva, (2003), com eventuais interações eólicas mais proeminentes em direção ao topo da sucessão.

O Aqüífero Caiuá tem extensão regional, sendo considerado livre a semiconfinado e contínuo (DAEE,1979). Condições de semiconfinamento são observadas nas porções onde fácies argilosas típicas da Formação Pirapozinho intercalam-se à Formação Caiuá, ou onde esta última encontra-se sobreposta por outras unidades aqüíferas do Sistema Bauru. O inter-relacionamento entre fácies arenosas e fácies pelíticas, observado nos perfis geofísicos disponíveis, torna o Aquíffero Caiuá heterogêneo e anisotrópico, ao menos na área abrangida por esta pesquisa.As figuras 6 e 7 mostram, respectivamente, a distribuição das isólitas de arenito de elevada e de moderada permeabilidade aparente do Aqǘf́ero Caiuá no Estado de São Paulo, elaboradas a partir da interpretação de perfis geofísicos. Os arenitos de elevada permeabilidade aparente mostram maiores espessuras concentradas na porção sudoeste da área de ocorrência do Sistema Aquífero Bauru no Estado de São Paulo, atingindo um máximo de 60 metros, enquanto as maiores espessuras de arenitos de moderada permeabilidade aparente encontram-se ligeiramente deslocados para leste, alcançando valores máximos de 40 metros. As isólitas totais máximas de arenito desta unidade hidroestratigráfica concentram-se na porção sudoeste do estado, alcançando valores da ordem de 80 metros (PAULA e SILVA, 2003). A distribuição das isólitas arenosas do Aqüífero Caiuá distingue a região do Pontal do Paranapanema (extremo sudoeste paulista) como de melhor potencial hídrico exploratório. 


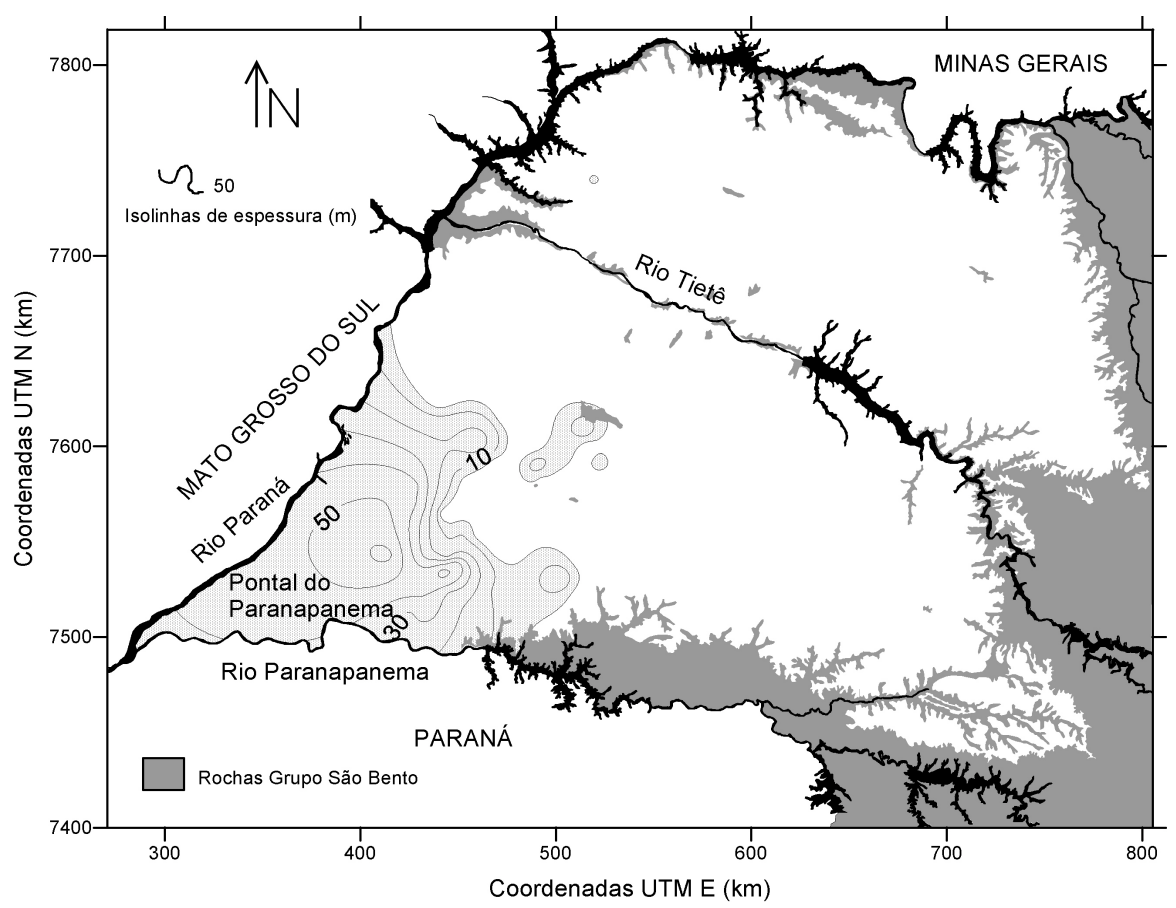

Figura 6 - Isólitas de arenito de elevada permeabilidade aparente do Aqüífero Caiuá (modificado de PAULA e SILVA, 2003).

Figure 6 - Sandstone isoliths of high apparent permeability of the Caiuá Aquifer (modified of PAULA e SILVA, 2003).

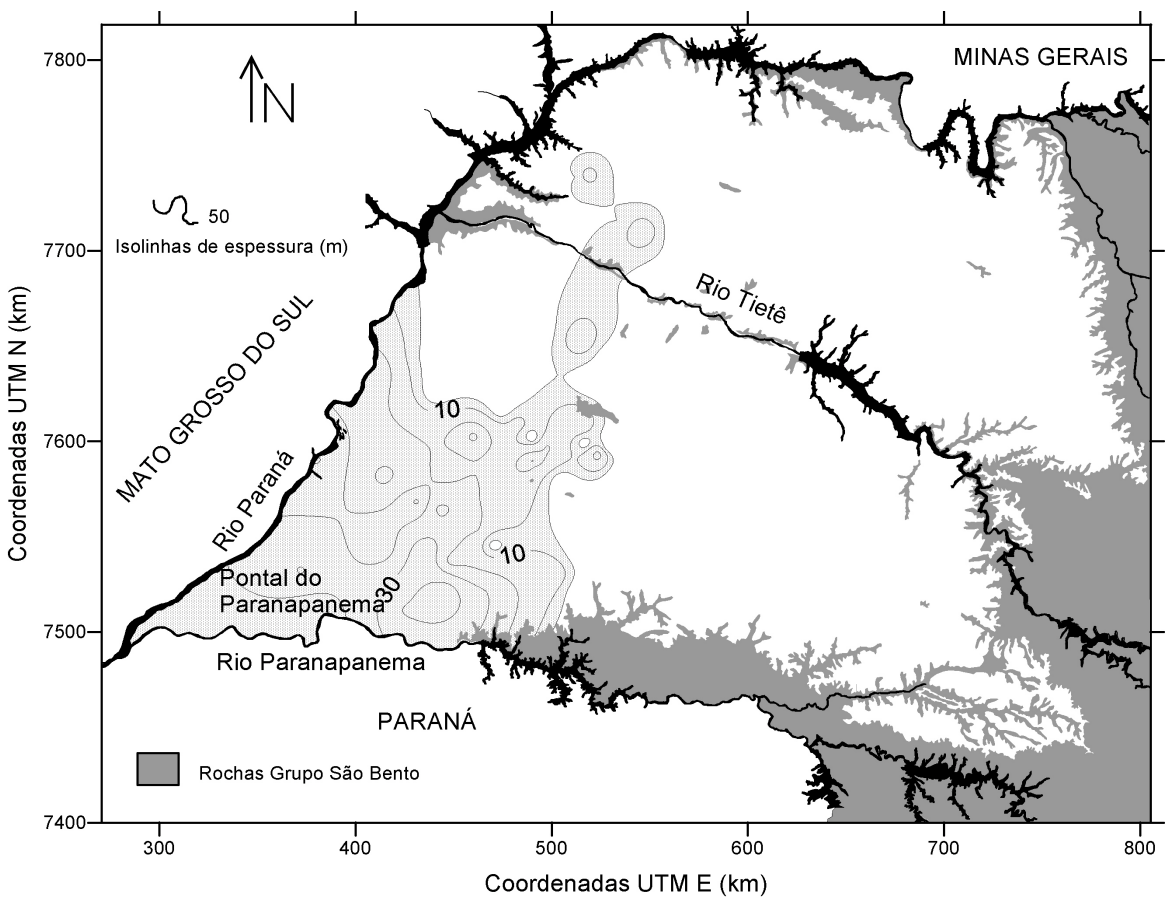

Figura 7 - Isólitas de arenito de moderada permeabilidade aparente do Aqüífero Caiuá (modificado de PAULA e SILVA, 2003).

Figure 7 - Sandstone isoliths of moderate apparent permeability of the Caiuá Aquifer (modified of PAULA e SILVA, 2003).

\section{Aqüífero Santo Anastácio}

O Aqüífero Santo Anastácio é representado pelos sedimentos preponderantemente arenosos da formação homônima, depositados por sistema fluvial entrelaçado com variações para meandrante, geralmente com raras intercalações pelíticas. Interações eólicas podem ocorrer no terço superior do aquíf́ero.
Sua área de afloramentos estende-se em estreita faixa paralela ao Rio Paraná, mas em subsuperfície avança na direção oriental até os limites do Alto de Tanabi, e sobre as regiões que constituem o Alto de Paraguaçu Paulista e a Depressão de Rio Preto, perfazendo extensão de cerca de $67.000 \mathrm{~km}^{2}$ (PAULA e SILVA, 2003). 
O Aqüífero Santo Anastácio apresenta extensão regional, sendo considerado livre a semiconfinado e contínuo (CETESB, 1997). Condições de semiconfinamento são encontradas nas porções onde está recoberto pelo Aqüitardo Araçatuba ou por camadas pelíticas atribuídas ao Aqüífero Adamantina. Onde as intercalações argilo-siltosas ocorrem com maior frequiência, manifesta comportamento heterogêneo e anisotrópico, mas pode mostrar certa homogeneidade em áreas quase exclusivamente dominadas por litossomas arenosos.

As figuras 8 e 9 mostram, respectivamente, a distribuição das isólitas de arenito de elevada e de moderada permeabilidade aparente do Aquífero Santo Anastácio no Estado de São Paulo elaboradas através da interpretação de perfis geofísicos.

Os arenitos de elevada permeabilidade aparente são predominantes e atingem espessuras máximas da ordem de 80 metros, concentradas na porção sudoeste do estado. Já o mapa de isólitas de arenito de moderada permeabilidade aparente apresenta distribuição relativamente homogênea, com alguns máximos em pontos localizados. A exemplo do Aqüífero Caiuá, o Aqüífero Santo Anastácio também apresenta potencial exploratório maior na porção sudoeste de sua área de ocorrência.

\section{Aquiífero Birigui}

O Aquífero Birigüi é representado por sedimentos arenosos de granulometria desde fina até conglomerática, depositados em ambiente fluvial de elevada energia, do tipo entrelaçado, atribuídos à Formação Birigüi (PAULA e SILVA, 2003). De ocorrência exclusiva em subsuperfície na porção central da bacia Bauru no Estado de São Paulo, esta formação ocupa área total estimada em $10.500 \mathrm{~km}^{2}$ e mostra-se estratigraficamente confinada pelos basaltos da Formação Serra Geral, abaixo, e pelos lamitos da Formação Araçatuba, acima (PAULA e SILVA, 2003).

Como aqǘfero, esta unidade pode ser considerada de extensão local, confinada e contínua. Variações em suas características granulométricas conferem heterogeneidade e anisotropia aos parâmetros hidrodinâmicos. A distribuição dos arenitos de elevada e de moderada permeabilidades aparentes é mostrada nas figuras 10 e 11 , respectivamente.

Neste aqüífero, as zonas com melhor potencial hídrico concentram-se em faixa alongada na região central de ocorrência da unidade. Esta aqüífero alcança espessura máxima da ordem de 50 metros (PAULA e SILVA, 2003).

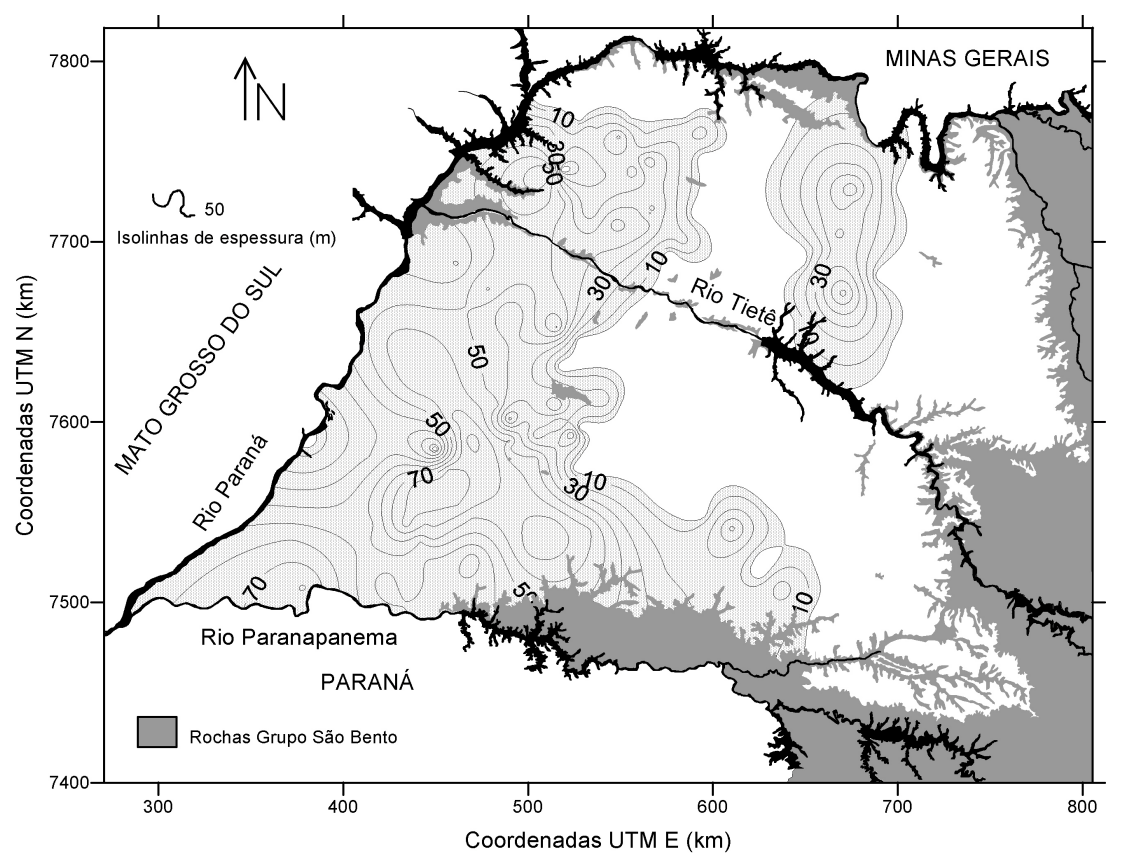

Figura 8 - Isólitas de arenito de elevada permeabilidade aparente do Aqüífero Santo Anastácio (modificado de PAULA e SILVA, 2003).

Figure 8 - Sandstone isoliths of high apparent permeability of the Santo Anastácio Aquifer (modified of PAULA e SILVA, 2003). 


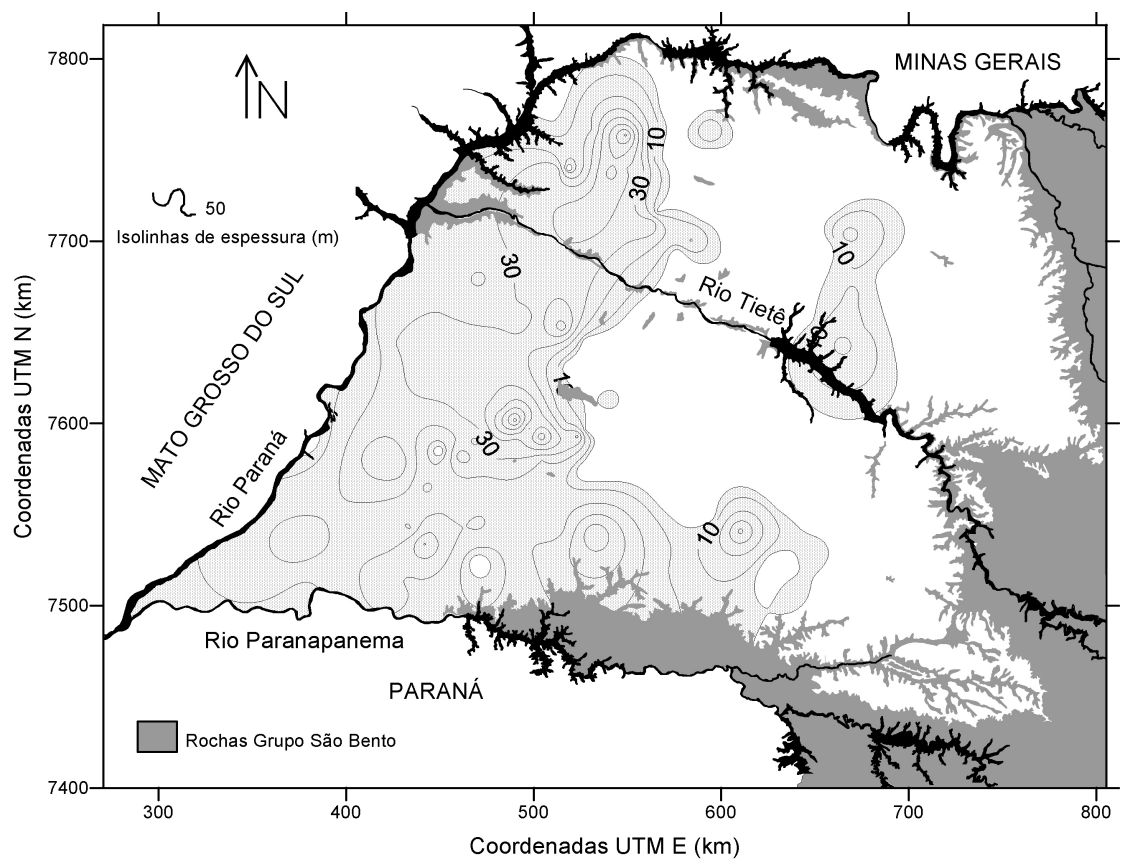

Figura 9 - Isólitas de arenito de moderada permeabilidade aparente do Aqüífero Santo Anastácio (modificado de PAULA e SILVA, 2003).

Figure 9 - Sandstone isoliths of moderate apparent permeability of the Santo Anastácio Aquifer (modified of PAULA $e$ SILVA, 2003)

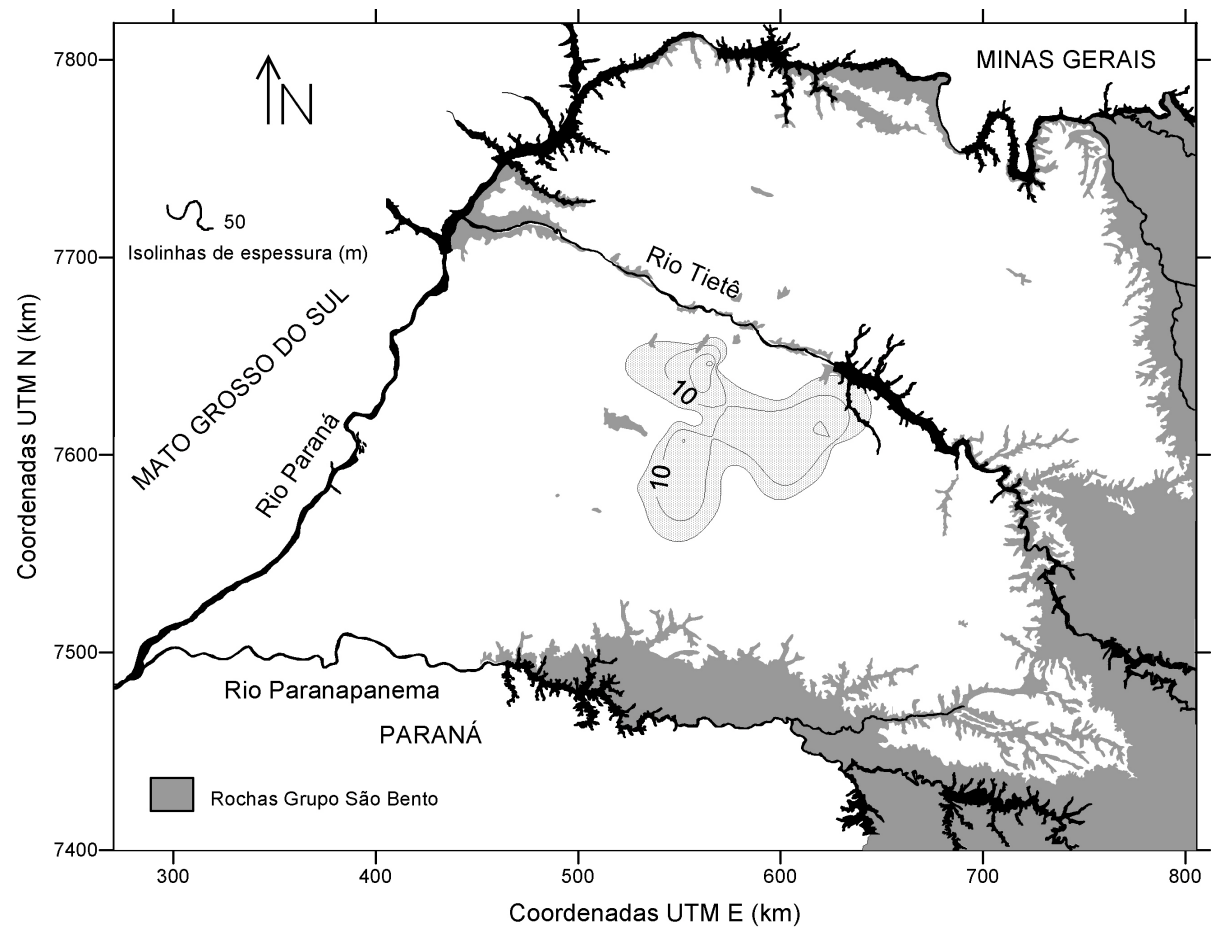

Figura 10 - Isólitas de arenito de elevada permeabilidade aparente do Aqüífero Birigüi (modificado de PAULA e SILVA, 2003).

Figure 10 - Sandstone isoliths of high apparent permeability of the Birigüi Aquifer (modified of PAULA e SILVA, 2003). 


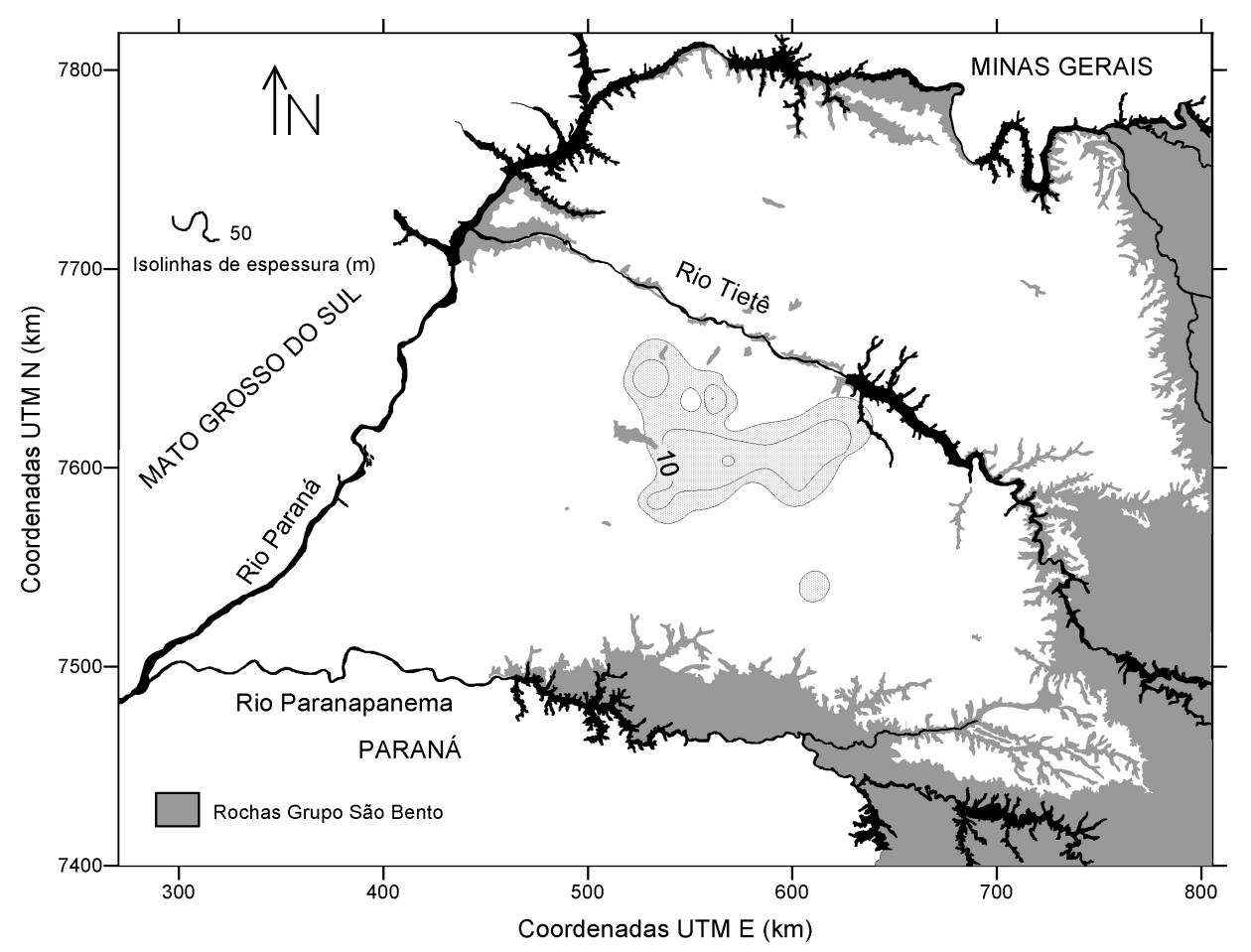

Figura 11 - Isólitas de arenito de moderada permeabilidade aparente do Aqüífero Birigüi (modificado de PAULA e SILVA, 2003).

Figure 11 - Sandstone isoliths of moderate apparent permeability of the Birigüi Aquifer (modified of PAULA e SILVA, 2003).

\section{Aquiífero Adamantina}

O Aquíífero Adamantina é representado por depósitos arenosos em ciclos de fining upward com terminação em pelitos, indicativos de sedimentação em canais fluviais meandrantes. A sucessão, como um todo, mostra padrão de coarsening upward constituindo ciclos maiores, indicativo de progradação do sistema fluvial sobre nível de base lacustre, podendo representar depósitos associados a pequenos deltas, onde os processos de progradação e regressão são controlados, respectivamente, pela retração e expansão do sistema lacustre (PAULA e SILVA et al., 2004).

Ocorre extensivamente em superfície, compreendendo área de aproximadamente 99.600 $\mathrm{km}^{2}$, estando coberto apenas localmente pela Formação Marília e ausente, por erosão, no extremo sudoeste paulista (PAULA e SILVA, 2003).

O Aquíifero Adamantina apresenta extensão regional, sendo considerado livre a semiconfinado e contínuo (DAEE, 1976). O semiconfinamento é decorrente principalmente das variações de permeabilidade dos sedimentos em função do maior ou menor teor de argila da matriz, ou de camadas pelíticas que se intercalam aos corpos arenosos.
A freqüência das camadas lamíticas e as variações de argilosidade dos arenitos desta unidade hidroestratigráfica determinam seu comportamento hidráulico bastante heterogêneo e anisotrópico, mesmo em localidades relativamente próximas (PAULA e SILVA, 2003).

As figuras 12 e 13 mostram a distribuição das isólitas de arenito de elevada e de moderada permeabilidade aparente, respectivamente, do Aquiífero Adamantina no Estado de São Paulo.

Nesta unidade aquífera, predominam os sedimentos de permeabilidade aparente moderada, com pontos de máximos irregularmente distribuídos em faixas paralelas, a sul e a norte do Rio Tietê (Figura 13). Os arenitos de elevada permeabilidade aparente comparecem em menor volume e apresentam isólitas irregularmente distribuídas, ligeiramente mais concentradas na região de São José do Rio Preto (Figura 12). Os sedimentos pouco permeáveis, presentes nesta unidade aquiífera, concentram-se em faixa a norte do Rio Tietê (PAULA e SILVA, 2003). A somatória das isólitas de arenito de elevada e de moderada permeabilidade aparente (isólitas totais) do Aquíffero Adamantina mostra máximos concentrados na região de São José do Rio Preto (PAULA e SILVA, 2003). 


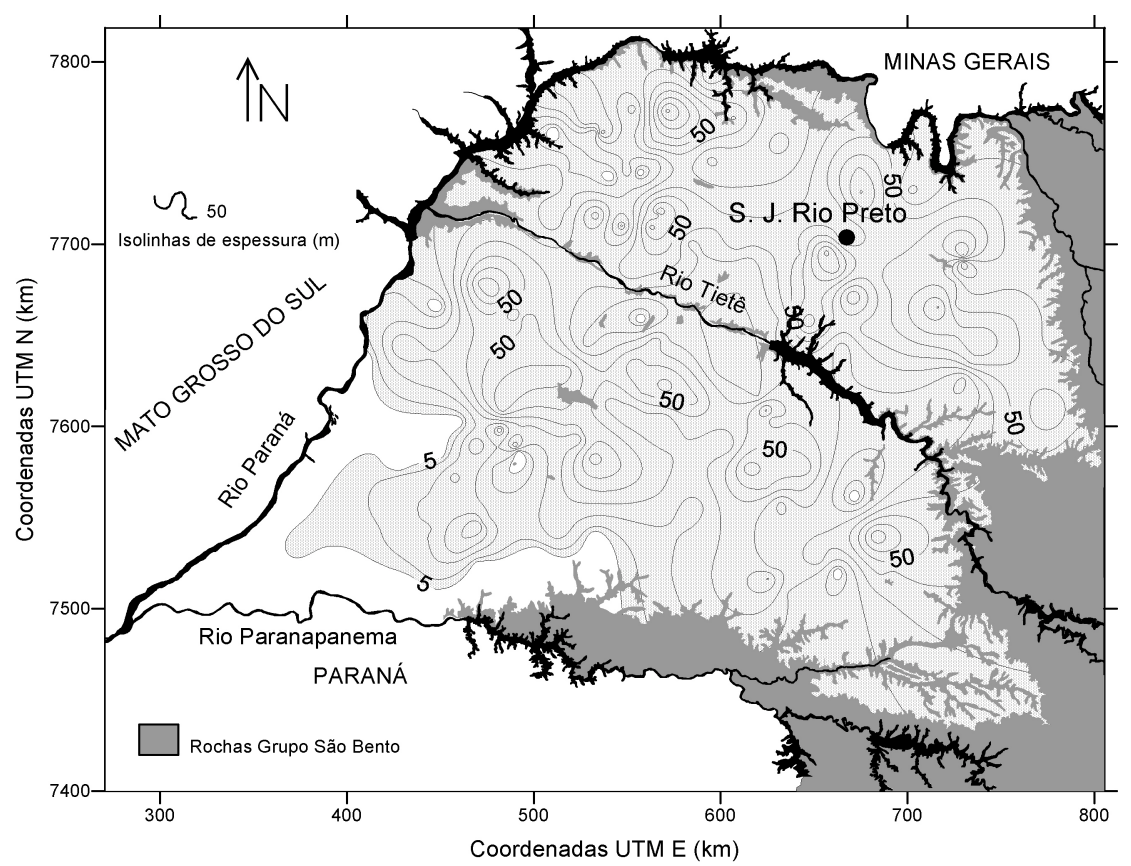

Figura 12 - Isólitas de arenito de elevada permeabilidade aparente do Aqüífero Adamantina (modificado de PAULA e SILVA, 2003).

Figure 12 - Sandstone isoliths of high apparent permeability of the Adamantina Aquifer (modified of PAULA e SILVA, 2003).

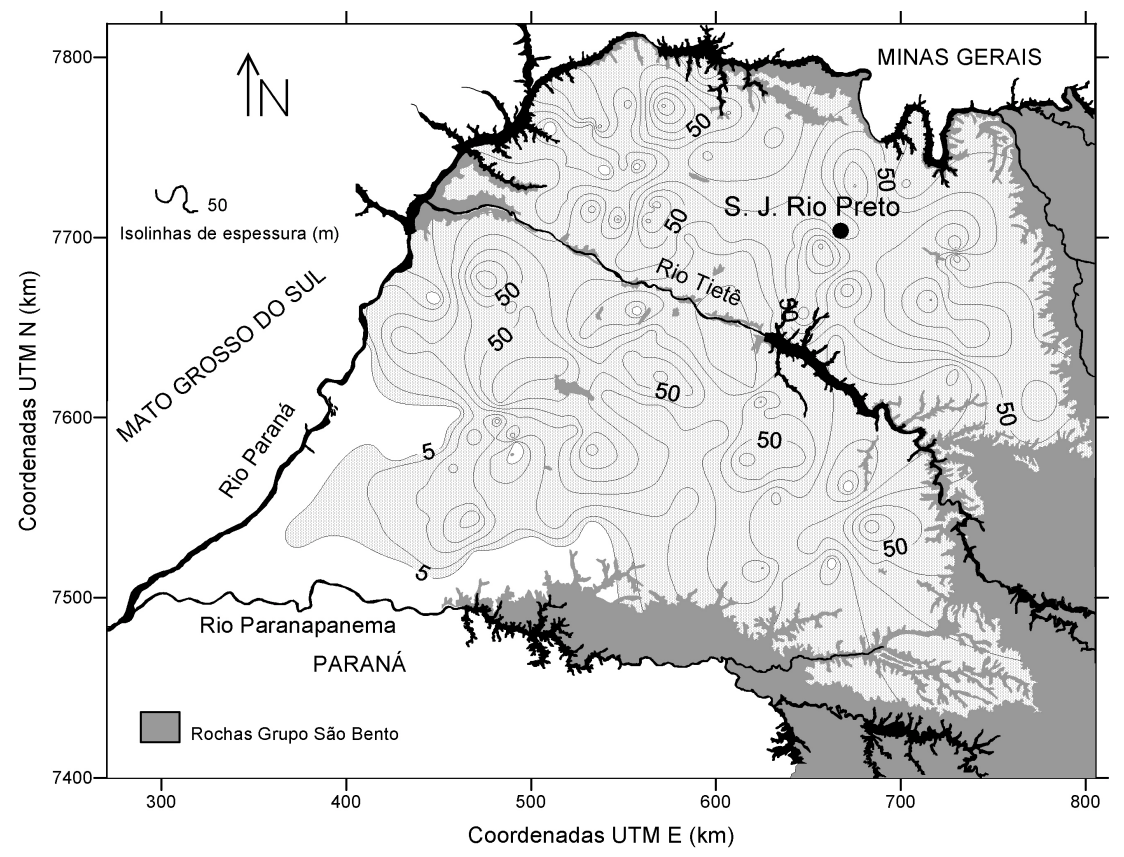

Figura 13 - Isólitas de arenito de moderada permeabilidade aparente do Aqüífero Adamantina (modificado de PAULA e SILVA, 2003).

Figure 13 - Sandstone isoliths of moderate apparent permeability of the Adamantina Aquifer (modified of PAULA e SILVA, 2003).

\section{Aqüífero Marília}

O Aqüífero Marília mostra extensão reduzida, com área preservada estimada de cerca de $15.000 \mathrm{~km}^{2}$, situado aproximadamente na porção centro-sul da área de ocorrência do Grupo Bauru no Estado de São Paulo, entre os rios Tietê e Paranapanema, e na região de Monte Alto (onde a insuficiência de dados de subsuperfície não permite análise adequada).
A unidade comporta sucessão relativamente homogênea, predominantemente arenosa, de granulometria fina a grossa, com baixo conteúdo argiloso e intercalações delgadas de material pelítico. Intensa cimentação carbonática é verificada, principalmente, nas porções superiores da formação (PAULA e SILVA, 2003).

O Aquífero Marília pode ser considerado de extensão regional, livre a semiconfinado e 
contínuo (DAEE, 1979). A intensidade variável da cimentação de seu arcabouço litológico conduz a variações de permeabilidade que o tornam heterogêneo e anisotrópico, e podem dar origem a situações de confinamento hidráulico. Também é comum, nesta sucessão, a formação de aqüíferos suspensos nas zonas de alteração superficiais da unidade, devido à presença de estratos subjacentes relativamente impermeáveis, isolando o corpo aquoso principal (DAEE, 1979).

O Aqüífero Marília mostra isólitas totais de arenito com máximos concentrados na região de Marília (SP), podendo alcançar cerca de 160 metros de espessura (Figura 14). A quantidade de pelitos presentes neste aqüífero é pequena e homogeneamente distribuída (PAULA e SILVA, 2003). Os perfis de resistividade analisados refletem, principalmente, a intensa cimentação carbonática dos constituintes litológicos, e não as porções mais permeáveis desta unidade aquífera, fato que dificulta a distinção entre arenitos de elevada e de moderada permeabilidade aparente com a utilização apenas desta ferramenta. Esta questão poderá ser solucionada com o estudo das relações entre $\mathrm{o}$ fator de formação $\mathrm{e}$ a resistividade da água das zonas aqüíferas, quando houver dados disponíveis.

Embora esta unidade hidroestratigráfica seja predominantemente arenosa e tenha grande espessura, as características hidráulicas estão fortemente afetadas pela cimentação carbonática, resultando em significativa diminuição dos valores de permeabilidade, conforme atestado pela pequena produtividade de poços profundos, da ordem de 5 a $10 \mathrm{~m}^{3} / \mathrm{h}$ em média (DAEE, 1979). Por esta razão, os arenitos do Aqüífero Marília podem ser classificados predominantemente como de moderada permeabilidade aparente.

\section{Estimativa das reservas permanentes das unidades} hidroestratigráficas do Sistema Aqǘfero Bauru

A estimativa das reservas permanentes das unidades hidroestratigráficas do Sistema Aqǘ́fero Bauru foi elaborada com base nos mapas de isólitas de permeabilidade aparente dos corpos arenosos, distinguidos nos perfis geofísicos. Uma vez calculado o volume dos sedimentos arenosos, foi considerada porosidade efetiva de $20 \%$ para as isólitas de permeabilidade aparente elevada e de $15 \%$ para as isólitas de permeabilidade aparente moderada, estimadas com base nas porosidades totais registradas pelos perfis sônicos, em média, da ordem de $25 \%$. Os resultados encontram-se ilustrados na figura 15.

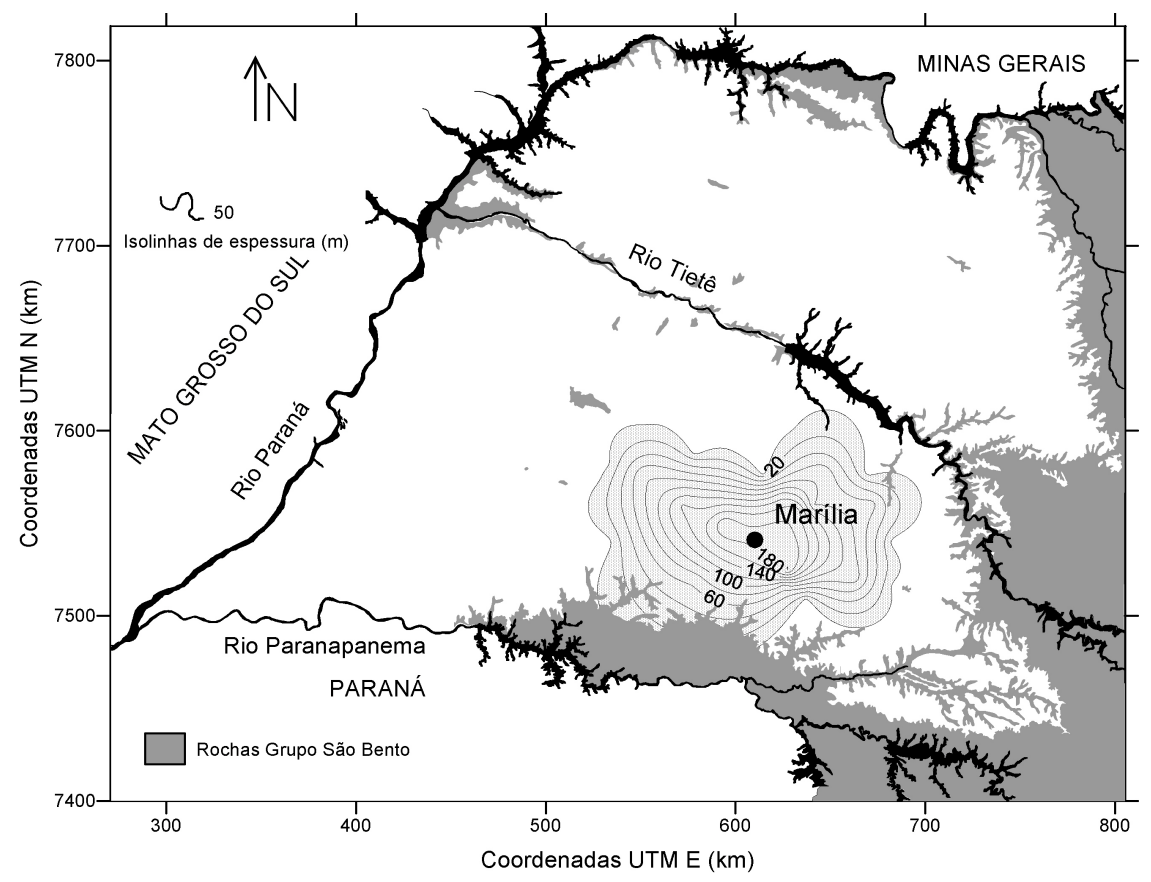

Figura 14 - Isólitas totais de arenito do Aqüífero Marília (modificado de PAULA e SILVA, 2003). Figure 14 - Sandstone total isoliths of the Marília Aquifer (modified of PAULA e SILVA, 2003). 


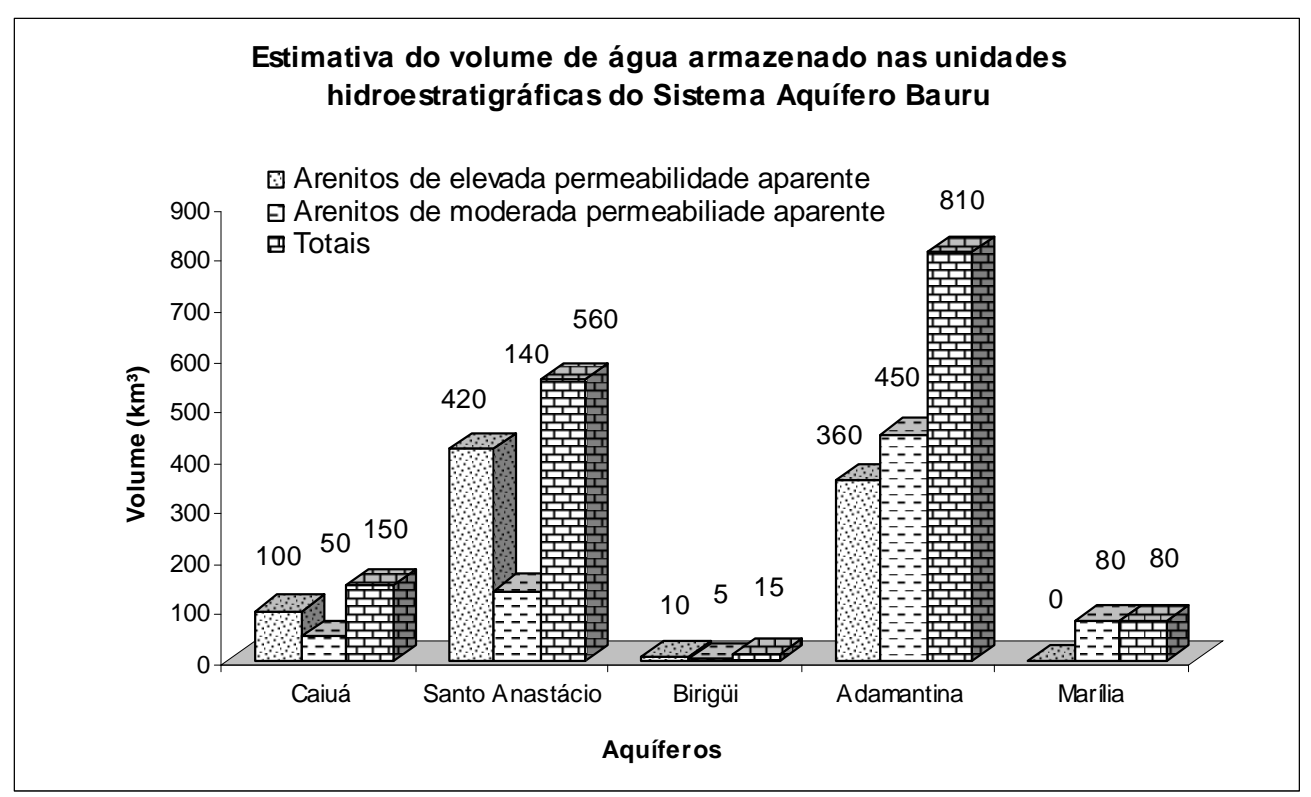

Figura 15 - Estimativa do volume de água armazenado nas unidades hidroestratigráficas do Sistema Aqüífero Bauru.

Figura 15 - Estimate of the volume of water stored in the hydrostratigraphic units of the Bauru Aquifer System.

As estimativas realizadas mostraram que o volume de água armazenado no Sistema Aqüífero Bauru alcança pouco mais de $1.600 \mathrm{~km}^{3}$, distribuídos em arenitos de elevada e de moderada permeabilidade aparentes. Os sedimentos classificados como de elevada permeabilidade armazenam pouco mais da metade $(55 \%)$ da água, correspondendo a volume de $890 \mathrm{~km}^{3}$.

O Aqüífero Adamantina, graças à sua extensa área de ocorrência, responde por $50 \%$ do volume armazenado em todo sistema, o que demonstra sua grande importância estratégica, ainda que as vazões fornecidas mostrem-se extremamente variáveis (DAEE, 1976, 1979).

Os aquíferos Santo Anastácio e Caiuá, considerados de melhor potencial exploratório para captação através de poços profundos, comportam respectivamente $35 \%$ e $9 \%$ do volume armazenado no Sistema Bauru, correspondendo a 560 e $150 \mathrm{~km}^{3}$ de água. Juntos, perfazem $44 \%$ das reservas hídricas do Sistema Aqüífero Bauru.

O Aqǘf́ero Marília possui extensão reduzida e arenitos muito cimentados, moderadamente permeáveis, acumulando reservas de apenas 80 $\mathrm{km}^{3}$, equivalente a $5 \%$ das reservas de todo sistema. As menores reservas hídricas estão armazenadas no Aqüífero Birigüi, de extensão reduzida, estimadas em $15 \mathrm{~km}^{3}$, ou menos de $1 \%$ das reservas de todo Sistema Aqüífero Bauru.

Os resultados desta estimativa de volumes permanentes estocados no Sistema Aqüífero Bauru, perfazendo um total de cerca de 1.600 $\mathrm{km}^{3}$, indicam que o armazenamento de água do aqüífero como um todo é suficiente para abastecer cerca de 180 milhões de pessoas, durante cem anos.

\section{CONCLUSÕES}

O Sistema Aqüífero Bauru apresenta comportamento hidrodinâmico heterogêneo em razão de sua variedade litofaciológica. Estudos realizados com perfis geofísicos permitiram distinguir unidades hidroestratigráficas regionais do Sistema Aqüífero Bauru, no Estado de São Paulo. A subdivisão hidroestratigráfica, baseada na litoestratigrafia de subsuperfície, justifica-se em razão das particularidades litológicas de cada formação que, por sua vez, influenciam as propriedades hidráulicas do meio poroso. Neste estudo, foram reconhecidos e distinguidos os aqüíferos Caiuá, Santo Anastácio, Birigüi, Adamantina e Marília, e os aquiitardos Pirapozinho e Araçatuba.

A avaliação das potencialidades das unidades hidroestratigráficas do Sistema Aqüífero Bauru baseou-se na espessura e características geofísicas mensuradas pelos perfis. As unidades aquíferas foram diferenciadas em termos de isólitas de permeabilidade aparente relativa dos sedimentos, em muito permeáveis e moderadamente permeáveis. Uma vez que transmissividade é definida como o produto da espessura pela condutividade hidráulica, os mapas de isólitas refletem, diretamente, as regiões potencialmente mais favoráveis à produção de água.

Os aquíferos Caiuá e Santo Anastácio apresentaram isólitas de arenitos com melhores 
características de permeabilidade aparente concentradas na região sudoeste, enquanto o Aqǘf́fero Birigüi, de expressão areal reduzida, mostrou de isólitas de melhor potencial hídrico concentradas em faixa alongada na porção central da área de ocorrência do Grupo Bauru. Para o Aqüífero Adamantina, as isólitas de moderada a elevada permeabilidade aparente mostraram zonas de maior potencial hídrico distribuídas em faixas paralelas, a sul e a norte do Rio Tietê. Para o Aqüífero Marília, os perfis de resistividade analisados refletiram, principalmente, a intensa cimentação carbonática dos constituintes litológicos, dificultando a distinção entre arenitos de elevada e de moderada permeabilidade aparente.

As reservas permanentes de água do Sistema Aquífero Bauru foram estimadas em pouco mais de $1.600 \mathrm{~km}^{3}$, distribuída pelos aqüíferos Caiuá $\left(150 \mathrm{~km}^{3}\right)$, Santo Anastácio $\left(560 \mathrm{~km}^{3}\right)$, Birigüi $\left(15 \mathrm{~km}^{3}\right)$, Adamantina $\left(810 \mathrm{~km}^{3}\right)$ e Marília $(80$ $\left.\mathrm{km}^{3}\right)$. 


\section{REFERENCIAS}

ARID, F.M. A Formação Bauru na região norteocidental do Estado de São Paulo. Geociências. São Paulo. v.1: 1-126, 1966.

BALAN, B.; MOHAGHEGH, S.; AMERI, S. Stateof-the-art in permeability determination from well log data: part 1 - a comparative study, model development. SOCIETY OF PETROLEUM ENGINEERS - SPE, Morgantown, West Virginia. SPE 30978. p. 1-10, 1995.

BARCELOS, J.H.; SUGUIO, K. Correlação e extensão das unidades estratigráficas do Grupo Bauru definidas em território paulista, nos estados de Minas Gerais, Goiás, Mato Grosso do Sul e Paraná. SIMPÓSIO REGIONAL DE GEOLOGIA, 6, Rio Claro. Atas... p. 313-321, 1987.

BARCHA, S.F. Aspectos geológicos e províncias hidrogeológicas da Formação Bauru na Região norte-ocidental do Estado de São Paulo. Instituto de Biociências, Letras e Ciências Exatas. Universidade Estadual Paulista (Tese Livre Docência). São José do Rio Preto. 209p, 1980.

BATEZELLI, A.; PERINOTTO, J.A.J.; ETCHEBEHERE, M.L.C.; FULFARO, V.J.; SAAD, A.R. Redefinição litoestratigráfica da unidade Araçatuba e da sua extensão regional na Bacia Bauru, Estado de São Paulo, Brasil. SIMPÓSIO SOBRE O CRETÁCEO DO BRASIL, 5 ; SIMPÓSIO SOBRE EL CRETÁCICO DE AMERICA DEL SUR,1, Serra Negra. Boletim... p. 195-200, 1999.

COMPANHIA DE TECNOLOGIA DE SANEAMENTO AMBIENTAL - CETESB Uso das águas subterrâneas para abastecimento público no Estado de São Paulo. São Paulo, 1997.

DEPARTAMENTO DE ÁGUAS E ENERGIA ELÉTRICA - DAEE Estudo de águas subterrâneas, regiões administrativas 7, 8 e 9: Bauru, São José do Rio Preto e Araçatuba. São Paulo: v.1 e v.2, 1976

DEPARTAMENTO DE ÁGUAS E ENERGIA ELÉTRICA - DAEE Estudo de águas subterrâneas, regiões administrativas 10 e 11: Presidente Prudente e Marília. São Paulo: v.1 e v.2, 1979

DEPARTAMENTO DE ÁGUAS E ENERGIA ELÉTRICA - DAEE Plano estadual de recursos hídricos: Primeiro plano do Estado - Síntese. São Paulo, 1990.

FERNANDES, L.A. A cobertura cretácea suprabasáltica no Paraná e Pontal do Paranapanema (SP): os grupos Bauru e Caiuá. Instituto de Geociências. Universidade de São Paulo USP (Dissertação de Mestrado). São Paulo. 129p, 1992

FERNANDES, L.A. Estratigrafia e evolução geológica da parte oriental da Bacia Bauru (Ks, Brasil). Instituto de Geociências. Universidade de São Paulo - USP (Tese de Doutoramento). São Paulo, 216p, 1998
FERNANDES, L.A.; COIMBRA, A. M. O Grupo Caiuá (Ks): revisão estratigráfica e contexto deposicional. Revista Brasileira de Geociências. São Paulo. v. 24 (n. 3): 164-176, 1994.

GUYOD, H. Interpretation of electric and gamma ray logs in water wells. The Log Analyst. v. 6 (n. 5): 2944, 1966.

INSTITUTO DE PESQUISAS TECNOLÓGICAS DO ESTADO DE SÃO PAULO - IPT Mapa geológico do Estado de São Paulo, escala 1:500.000. São Paulo, IPT, v.1 e v.2, 1981.

MEZZALIRA, S. Contribuição ao conhecimento da estratigrafia e paleontologia do arenito Bauru. Boletim do Instituto Geográfico e Geológico - IGG. São Paulo. v. 51: 162, 1974.

NERY, G.G. A perfilagem geofísica em poços tubulares para suprimento de água subterrânea. Hydrolog Serviços de Perfilagem Ltda., 1995.

PAULA e SILVA, F. Geologia de subsuperfície e hidroestratigrafia do Grupo Bauru no Estado de São Paulo. Tese de Doutorado. Instituto de Geociências e Ciências Exatas, Universidade Estadual Paulista. Rio Claro. 166 p., 2003.

PAUlA e SILVA, F.; CHANG, H.K.; CAETANOCHANG, M.R. Perfis de referência do Grupo Bauru (K) no Estado de São Paulo. Revista Geociências, v. 22 (número especial). Rio Claro. p. 21-32, 2003.

PAULA e SILVA, F.; CHANG, H.K.; CAETANOCHANG, M.R. - (2004) - Estratigrafia de subsuperfície do Grupo Bauru (K) no Estado de São Paulo. Revista Brasileira de Geociências (no prelo). SCHLUMBERGER LTD. Log interpretation: Principles. New York - USA, Schlumberger Ltd: v.1, 1972.

SCHLUMBERGER LTD. Log interpretation: Applications. New York - USA, Schlumberger Ltd: v.2, 1974.

SEABER, P. R. Hydrostratigraphic units. Hydrogeology. v. 0-2: 9-14, 1988.

SOARES, P. C.; LANDIM, P.M.B.; FÚLFARO, V.J.; SOBREIRO NETO, A.F. Ensaio de caracterização estratigráfica do Cretáceo no Estado de São Paulo: Grupo Bauru. Revista Brasileira de Geociências. São Paulo. v. 10 (n. 3): 177-185, 1980.

VIEIRA, P.C. Sugestões para estudo de captação de água subterrânea no Grupo Bauru: considerações tectônicas. Revista do Instituto Geológico - IG. São Paulo. v. 2 (2): 5-16, 1981. 
Hidroestratigrafia do Grupo Bauru (K) no Estado de São Paulo 